\title{
Aortic sponge sling to improve mitral exposure
}

\author{
Mehmet Ali Şahin (D), Erkan Kuralay (D) \\ Department of Cardiovascular Surgery, A Life Park Hospital, Ankara, Turkey \\ Received: September 17, 2020 Accepted: February 17, 2021 Published online: March 29, 2021
}

\begin{abstract}
Superior septal approach provides the best exposure of the mitral valve and is the preferred approach for mitral valve procedures. In the presence of the larger aorta, surgical exposure may be impeded during mitral valve surgery, even for forcefully suction of the aortic vent. Herein, we describe a simple maneuver to avoid this problem. Previously prepared a long sponge sling passed from transverse sinus after a cannulation procedure is completed and the slinged sponge is retracted leftward and superiorly immediately after aortic cross-clamping and cardioplegia infusion.

Keywords: Larger aorta, sponge sling, superior septal approach.
\end{abstract}

Superior septal approach provides the best exposure of the mitral valve. It is a preferred approach for all mitral operations. ${ }^{[1-3]}$ The incision on the left atrial dome is sometimes advanced to the beneath of the ascending aorta. Ascending aorta (particularly a large aorta of $>4 \mathrm{~cm}$ in size) may impede surgical exposure during mitral valve surgery. Despite forcefully aortic suction, mitral exposure cannot be sufficient in some cases. Herein, we describe a simple technique to avoid this unfavorable condition.

\section{SURGICAL TECHNIQUE}

Long sponge sling is passed from the transverse sinus after cannulation is completed (Figure 1a). The sling sponge is retracted leftward and superiorly immediately after aortic cross-clamping and cardioplegia infusion (Figure 1b). The sling is released during the subsequent cardioplegia administration. This simple maneuver easily improves the surgical exposure of the left atrial dome and, then, extended left atriotomy can be done more comfortably.

\section{DISCUSSION}

Although superior septal approach provides a better exposure, it carries certain limitations such as arrhythmias and bleeding. In particular, the dome of the left atrium has a friable tissue. Direct primary closure may cause suture disruption and intimidating bleeding. Using our technique, we sutured the dome
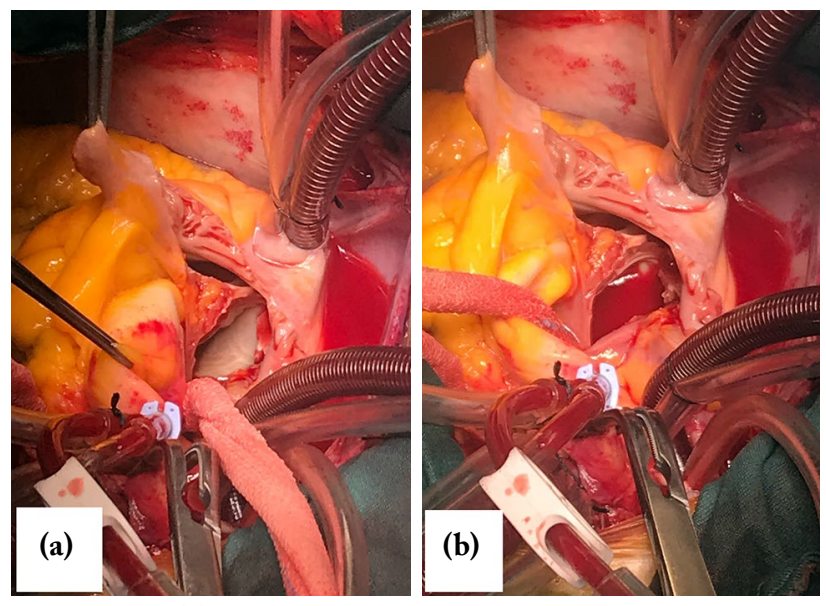

Figure 1. (a) Sponge sling passing from transverse sinus immediately after cannulation. (b) Sponge sling retracting leftward and superiorly immediately after aortic cross-clamping and cardioplegia infusion.

of the left atrium by pericardial buttressed sutures to avoid suture disruption and bleeding. Most surgeons do not use any retractors for extended left atrial mitral exposure. Four/six pledgeted sling sutures are placed

Corresponding author: Erkan Kuralay, MD. A Life Park Hastanesi Kalp ve Damar Cerrahisi Bölümü, 06790 Etimesgut, Ankara, Türkiye.

Tel: +90 533 - 2309656 e-mail: erkankuralay@gmail.com

\section{Citation:}

Şahin MA, Kuralay E. Aortic sponge sling to improve mitral exposure. Cardiovasc Surg Int 2021;8(1):68-69. 
into the interatrial septum and left atrial dome in both sides. However, the ascending aorta may impede surgical exposure, despite these pledgeted sling sutures. Automatic retractor system or Cosgrove mitral valve retractor or vein retractors (Kapp Surgical Instrument, Inc. Cleveland, $\mathrm{OH}, \mathrm{USA}$ ) can also be used to improve mitral valve exposure. However, additional retractors may not only increase the cost of surgery, but also disrupt the surgical field with instrument clutter and needs extra-hand. Retraction of the ascending aorta leftward and superiorly by sponge sling improves the surgical field until the root of the left atrial auricula. Based on our experience, our simple maneuver ensures a better surgical mitral exposure.

\section{Declaration of conflicting interests}

The authors declared no conflicts of interest with respect to the authorship and/or publication of this article.

\section{Funding}

The authors received no financial support for the research and/or authorship of this article.

\section{REFERENCES}

1. Utley JR, Leyland SA, Nguyenduy T. Comparison of outcomes with three atrial incisions for mitral valve operations. Right lateral, superior septal, and transseptal. J Thorac Cardiovasc Surg 1995;109:582-7.

2. Garcia-Villarreal OA. Superior septal approach for mitral valve surgery. Interact Cardiovasc Thorac Surg 2016;22:249-51.

3. Sultan I, Trivedi DP, Machiraju VR. Surgical approaches to the mitral valve: Variable paths to the same destination. Indian J Thorac Cardiovasc Surg 2018;34:105-12. 